\title{
The grammar of truth
}

\section{Inquiry (accepted, in press)}

Wolfram Hinzen, ICREA (Catalan Institution for Research and Advanced Studies), Universitat Pompeu Fabra, Departament de Traducció i Ciències del Llenguatge, Roc Boronat, 138, 08018 Barcelona, Spain, wolfram.hinzen@upf.edu

Martina Wiltschko, Department of Linguistics, The University of British Columbia, Totem Field Studios, 2613 West Mall, Vancouver, BC V6T 1Z4, Canada, Martina.Wiltschko@ubc.ca 
Abstract. Much philosophical attention has been devoted to the truth predicates of natural language and their logic. However, lexical truth predicates are neither necessary nor sufficient for a truthattribution to occur, which warrants closer attention to the grammar of truth attribution. A unified analysis of five constructions is offered here, in two of which the lexical truth predicate occurs (It's true that John left and That John left is true), while in the three remaining, it does not (John left; It seems that John left; and It's that John left). This analysis is philosophically significant for four reasons. First, it explains why speakers of natural language find standard instances of Tarski-inspired equivalences (e.g., That John left is true iff John left) intuitively compelling. Second, it derives the widespread 'deflationist' intuition that truth has no substantive content. Third, insofar as the deflationist sees insights on truth as flowing from understanding our practice of truth attribution, it furthers the deflationist agenda through a new analysis of such attributions. Finally, it advances the philosophical project of the 'naturalization' of truth by reducing our understanding of truth to our competence in the grammar of truth, as an aspect of our biological endowment.

Key words: truth, grammar, Tarski, deflationism 


\section{Introduction}

Consider a speaker asserting (1), with normal intonation:

(1) John left.

In (1), a single predicate is involved: 'left'. That same predicate, predicated of the same individual, is also present in (2), as schematically analysed in (3):

(2) Mary said John left.

(3) Mary said [John [Predicate left]]

But there is a crucial difference between (1) and (2): in (1), we are assuming that the speaker asserted that John left, and this would indeed be its normal use when (1) is uttered. In (2), by contrast, the same proposition is not asserted: (2) can only assert that Mary said John left. This difference is significant if we accept that assertion is the assertion of truth - in the sense that whoever asserts, asserts that something is true but not, say, possible, probable or valuable (which are logical possibilities, too, but arguably incorrect descriptions of what an act of asserting a sentence like (1) involves). A speaker after asserting (1) could not, when challenged about his assertion of (1), turn around and respond that he had not in fact claimed that it was true that John left, but only, say, that it was likely, or that he only meant to say that he believed this. To such responses the following rejoinders would be entirely appropriate: 'You said that John left, not that this was likely' or 'I don't care what you believed: I am talking about what you said'. In short, it is understood, in witnessing a normal utterance of (1), that (1) is indeed asserted as true, not as anything else - not as possible, desirable, being believed, or being useful, etc. The significance of this fact is although truth is involved in an assertion of (1), the notion of truth is nowhere lexically represented in (1). This shows that since it is present, its source cannot be lexical.

There is, in short, a certain proposition, that John left, and it is asserted as true in (1), but not in (2), and the question is why this contrast obtains. How does it come about? In what follows we will technically say that the speaker asserting (1) effects a truth-attribution, where 'truth-attribution' is a term used here to express the facts just rehearsed, which we take to be empirical ones about ordinary human language use and practice. The fact that will concern us is that the predication of truth is involved when (1) is asserted, while a large number of other logically possible evaluative predicates are all not. To be sure, a speaker asserting (1) will also typically believe what s/he says, and often also consider it likely. Yet we obtain a contradiction between an assertion of (1) and an assertion of This is not true or of John didn't 
leave, while there is no contradiction in a similar sense between (1) and You don't believe this, showing that truth and belief are involved in different ways. There is also no contradiction in the speaker's later comment: 'Well, I said that John left, but didn't really believe it' (though pragmatically, we would presumably trust such a speaker's assertions less). In assertions of This is not true or John didn't leave, what is being negated is the truth of a proposition, i.e. that John left, not its being believed. We flag up these differences between the belief and truth predicates here, to which we return further below in the next section.

The above entails that a lexical truth predicate is not necessary to effect a truth-attribution. How exactly truth is predicated, even if it is not present as a word (or lexically), is thus the central question we here address. It also turns out that the lexical truth predicate is not sufficient to effect a truthattribution. Thus, trivially, if the speaker had uttered (4), the lexical truth predicate would have been present and it would have been attributed to the very same proposition (i.e., that John left), but the speaker would not then have asserted that proposition:

(4) Bill considers it true that John left.

This demonstrates that the lexical truth predicate is not sufficient for a truth-attribution to occur, either: for this will also depend on the grammar of its occurrence. Had the speaker uttered (5), in turn, he would have attributed truth to (or asserted) the proposition that it is true that John left, and the proposition that John left only insofar as his commitment to that latter proposition would have followed by a familiar reasoning (if it is true that $\mathrm{P}$, then $\mathrm{P}$ ):

(5) It's true that John left.

Arguably, that is, to effect an attribution of truth to the proper proposition that John left, rather than another proposition that merely entails it, (1) is exactly what is needed. This is in line with what distinguishes (1) and (5): the question of whether John left is answered naturally by (1), not by (5), which makes sense in a context when (1) has already been asserted as true but something else has occurred, such as doubt about the truth or relevance of (1), which leads to its re-assertion. In this way, explicit truth-attributions as exemplified in (5), in which the lexical truth predicate occurs, thus asymmetrically depend on truth-attributions exemplified in (1), where no lexical predicate responsible for truth-attribution occurs. 
The conclusion at this point is that a lexical truth predicate is neither sufficient nor necessary for a truth-attribution to occur. But then how does truth-attribution come about? Section 2 considers and limits the scope of another potential source for truth-attribution, namely pragmatic inferencing. Section 3 asks how truth is attributed if this does not happen lexically. Section 4 derives a benefit from this account, which is that characteristic equivalences about truth such as It is true that John left iff John left (Horwich, 2010), are predicted to be judged correct by competent speakers of English. Sections 5 and 6 fine-grain this account by reviewing several grammatical constructions that systematically co-vary with how and whether truth is attributed, providing further evidence for the claim that truth-attribution is grammatically conditioned: if the ingredients of the grammatical constructions vary, the details for truth-attribution vary predictably. In Section 7 we turn to broader considerations of the status of truth in the architecture of grammar and metaphysical repercussions. Section 8 concludes with direct entailments of this analysis for the deflationist program in the philosophy of truth (e.g. Horwich, 2010).

\section{Truth as pragmatics}

It is also not a matter of choice or perhaps 'context' that, if (1) is chosen by a speaker, a truth-attribution to a particular proposition is effected. Whatever the context and whatever the speaker's intention, if she said (1), it isn't optional then to take her to have said that (1) is a probability, or her life's greatest wish, say. The effect in question in this way does not appear to be a pragmatic one. ${ }^{1}$ Rather, it is natural to express it by saying that an attribution of truth is inherent to the semantics of (1). Since there is no lexical truth predicate and the effect is not pragmatic it is natural to conclude that the fact that (1) effects a truth-attribution is an aspect of its grammar.

Against this, we should not be tempted to contend that the truth attributed in (1) is merely part of an implicit commitment that a speaker who asserts (1) shoulders. On this latter view, the commitment to the fact that the proposition that John left is true would be part of what can be logically derived from (1), perhaps using various auxiliary assumptions from speech act theory - but it would not be an inherent aspect of its grammar. This would then be similar to the speaker's implicit commitment to the

${ }^{1}$ The arguments presented here only hold if (1) is uttered with falling intonation typically associated with assertions. A change in intonation (e.g. a sentence-final rise) affects the assertoric force of the utterance. This will have to occur if a speaker seeks to avoid a commitment to the truth of what she says, just as a change in the grammar may correlate with a change in force as for example with conjectures (e.g. 'if John left...', 'Suppose John left', etc.). Assertions that occur in play-acting do not cause problems for the present account: play-acting an assertion is no more to assert something, than Herodes' palace on stage is Herodes' palace. 
belief that John left. The point of the contention would be that, surely, the predicate believe is not somehow involved in the grammar of (1) either. So why, the objection would continue, should this be more plausible in the case of the truth predicate? But we have already addressed this objection: This is not true, said in response to an assertion of (1), contradicts it. You don't believe this, does not, but questions the grounds of the assertion, thereby also casting doubt on its truth. Relatedly, as Tarski noted, 'snow is white' is true iff snow is white. In this sense, a sentence in which the lexical truth predicate occurs is equivalent to one where it does not occur. But no such neat equivalence has ever been found for the belief-predicate. This reinforces the contention that the two cases are different: in our assertoric use of snow is white, truth must somehow be predicated, which is why we get away with the equivalence. In contrast, belief is not. ${ }^{2}$

None of this is to say that the facts that we are here interested in cannot be modelled by using logic and speech act theory and deriving implicit commitments. The reason that we explore a different path is systematic evidence presented below that the facts in question are in fact grammatically regulated: truth-theoretic force, in an assertion, happens to co-vary closely with grammatical factors, in unsuspected and systematic ways. We will provide such evidence from a range of construction types. To begin with, consider (6):

(6) Bill said John left.

In (6), (1) identically occurs (or so it seems). But, of course, no truth is necessarily attributed to the proposition that John left by the speaker in this instance, as noted. Now, how can the effect we noted about (1) be 'inherent' to it, when (1) identically occurs in (6), but the effect is absent there? It can, if the effect is an aspect of its grammar: for the grammar of the string of words John left is of course different in the two cases, in a way that, as we shall argue here, also explains the interpretational difference. Thus, the grammar of (1) is not such that (1) functions as a syntactic argument; but as occurring in (6), its grammar is that of a syntactic argument (namely, of the matrix predicate said). Being a syntactic

\footnotetext{
${ }^{2}$ Relatedly, it is doubtful whether, as one referee wonders, truth attribution could follow from a norm of assertion, like that one should assert $p$ only if one knows $p$ (since knows- $p$ entails that $p$ is true). While norms can be flouted, the attribution of truth, if the grammatical configuration is right and normal intonation is used, cannot be. The response to an assertion: 'You don't really know that, why do you assert it?' is coherent. It objects to an assertion being made, but does not question that it was an assertion (and as such an assertion of truth). Lackey (2007: 599) points to examples of 'selfless assertion', which does not express a speaker's belief and hence is independent of 'knowledge'. This is not to say there is no interface between grammar and the norms of assertion, which in fact we consider crucial.
} 
argument is uncontroversially a grammatical property. While there is no lexical difference, therefore, there is a grammatical one. The latter, moreover, is completely systematic. It is a general fact about clausal arguments that they never effect an attribution of truth by the speaker: truth is asserted in matrix contexts only. ${ }^{3}$ For this reason, the truth attributed by the speaker in (6) is that Bill said something, i.e. that John left; but not that John left. In short, a truth-attribution is effected if the grammar is right; else, it isn't.

\section{Truth as configurational}

A comparison of (1) with (6) teaches another point: The predicate that we see overtly in (1), namely left, cannot itself be the truth predicate that we have claimed is involved, or 'absorb' it somehow: for this same predicate, i.e. 'left', is also present when (1) occurs in (6), but no truth is predicated of the embedded clause then, as noted. Therefore, the predication of truth involved in the attribution of truth that (1) encodes - however we will eventually think of it - is not part of (1)'s overt lexical specifications but comes in via a different route. The lexical truth predicates attached to (1) when the truths of, say, (4) or (5) are asserted, cannot be involved in the predication of truth in a truth-attribution by the speaker, because, in these assertions, what is asserted is not, strictly, that John left, but what (4) and (5) state. Again, therefore, just as in the case of (1), there is, in addition to the lexical predicates involved in (4) or (5), another source for the predication of truth involved in these sentences as used assertorically, which is not lexically expressed, but which is attributed to whatever proposition it is that is encoded.

Given the absence of a lexical truth predicate, and given that we have argued that the effect we have noted is an inherent aspect of the grammar of the expressions involved, we will put it in what follows that that the predication of truth is encoded structurally, or, in technical terms, configurational. It follows from the foregoing that the 'structural' predication of truth, which we claim is implicit in the grammar of any asserted sentence, cannot be substituted for by any lexical truth predicate that is overtly present in that sentence. ${ }^{4}$ Rather, it is irreducible and expresses truth merely through assembling a number of

\footnotetext{
${ }^{3}$ As Davidson (2005) stresses, only whole sentences are assigned truth values. Clauses embedded in complex sentences can of course refer to a fact that is presupposed to obtain, but this is different from asserting the proposition expressed by the embedded clause. Co-Author \& Author (2011) show that the grammar of clauses that are 'factive' is not a counterexample to the present claim, as both that grammar and the semantics of such clauses are different from those of non-factive embedded clauses. As also pointed out there, the explanation of factivity is not lexical-semantic either.

${ }^{4}$ There are two ways to technically implement the claim that the predication of truth is grammatically configured just as there have been two ways to linguistically encode the predication relation between a
} 
grammatical elements in the right configuration. Note that it is not, in general, surprising at all that some given concept should be able to be present both lexically and structurally in a language: the example of thematic roles will be discussed in this respect below (see (56)-(57)).

Our conclusions so far raise novel questions for the philosophy of truth, which has largely focused on what is said to be 'the truth predicate', by which always a lexical predicate is meant and whose meaning is usually conceptualized in semantic or metaphysical terms (see Moltmann, 2012, for discussion of the truth predicates of natural language). But clearly, given the above, the lexical truth predicate 'true' (or any other lexical truth predicate) cannot be the whole truth about truth-attributions: for that truth-attributions occur is, in general, not due to the contribution of the content of any particular lexical item. Rather, once again, it is due to the fact that grammatical elements come together in the right way: minimally, a subject, a predicate, and finite Tense. That these elements occur in the right grammatical configuration (in particular, not that of an embedded argument, as we have seen, and with normal intonation) is, it appears so far, both necessary and sufficient for a truth-attribution to occur. Truth as predicated in truth-attributions, therefore, is nothing lexical but something grammatical. ${ }^{5}$ In line with this, note further that all of the above elements of truth are grammatically defined; none is known in linguistic theory to be semantically explicable, or logically; and none is lexical. Thus, in particular, 'subject' is a configurational and relational notion that depends on the geometry of the phrase structure of the clause. No phrase (let alone word) is a subject, intrinsically; rather, a phrase is a subject only in the context of a sentence and relative to a given (sentential) predicate (technically, a TP or tense phrase). No phrase is a subject for any lexical or semantic reason either. Thus noun phrases denoting agents need not be subjects, as e.g. in passives (The ball was kicked by the child), where they are adjuncts, and noun phrases that are expletives can be subjects (It is raining. It seems that John left). In turn, noun-phrases

subject and its predicate. It may be merely a function of a structural configuration (as for example in Williams' (1980) analysis of small clauses) or it may be mediated by a dedicated head (lexical or abstract) whose function is to relate the subject in its specifier position to the predicate in its complement position (as for example in Stowell's (1981) or Den Dikken's (2006) analyses). In sections 56 we opt for the former approach, identifying this relation with a structural configuration: see also Author (2003), Co-Author and Author (2015). For abstract functional heads that have been posited in the grammar of truth, see e.g. Laka's (1994) or Höhle (1992).

${ }^{5}$ One cannot state a truth using a word only, including the word true. One can of course say the single word True. But this will only be felicitous if it is a reply to a truth attribution, which needs to take a sentential form. This account raises the important question of whether a truth attribution can be effected through sentence fragments, which as such fail to replicate the core elements of the grammatical configurations reviewed above and below. Author (2015) contains an argument against this option, suggesting that differences in sentential grammar always correlate with a difference in meaning. 
that are object-referential are not necessarily subjects either (but can e.g. be objects), and phrases not denoting objects (e.g. clauses) can be subjects. ${ }^{6}$

Similar remarks apply to the predicate that is necessarily part of a truth configuration in the sense above: the term 'predicate' specifies a way in which a given phrase grammatically functions, and is again independent of both lexical and phrasal category, and of lexical semantic content. Thus predicates can be nouns (He is a man), verbs (He sleeps), adjectives (He is sleepy), or clauses (He is what you think he is; The man who has a hat). One could attempt to define the term 'predicate' semantically (e.g. through the notion of membership in a set denoted by the predicate), or metaphysically (e.g., through the notion of 'denoting a 'property'), without invoking, explicitly or implicitly, the grammatical notion of a predicate. This would show that the notion of predicate is not inherently a grammatical one, yet Davidson (2005) reviews two thousand years of failures in this attempt. This is no argument that we might not succeed in some such semantic definition of an inherently grammatical notion eventually. For present purposes, all we need to note is that the crucial elements empirically observed in a truth-attribution (subject, predicate, finite Tense, in the right configuration) are, prima facie, grammatical ones - whatever the deeper, non-grammatical senses might be that correspond to them. Tense, too, of course, is a grammatical notion, relating a subject with a predicate and localizing the resulting proposition in time relative to the time of speech (Sigurdsson, 2004). ${ }^{7}$ Where (finite) Tense is missing in a clause, as in the small clause (SC) in John considers [sc him [a man]], or the matrix clause John leave, no truth is attributed to the clauses him a man or John.

\section{Deriving Tarskian equivalence schemata}

It follows from the above that grammar should clearly become a part in thinking about the notion of truth. An immediate benefit of this grammatical perspective is an explanation for why (7) is commonly taken to be true, to which we now turn.

(7) That John left is true iff John left.

${ }^{6}$ Though there is an unsettled controversy whether clauses that appear to be subjects are indeed subjects. Emonds (1976) takes such clauses to always be topics (cf. also Koster, 1978; Stowell, 1981; Safir, 1985) whereas Rosenbaum (1967); Emonds (1972); Delahunty (1983) and Davies \& Dubinsky (2009) argue that they are genuine subjects (see Lohndal, 2013, for a recent overview).

${ }^{7} \mathrm{In}$ line with its status as a grammatical notion, Tense can remain expletive (i.e., temporally uninterpreted). This is the case in counterfactual conditional, for example, where past tense marking is compatible with an adverb of present time (If I had a car now) and hence is fake (Iatridou, 2000). 
Ordinary speakers tend to find this assertion compelling (even if non-illuminating). But why should (7) be true? Why should something that contains a truth predicate be logically equivalent to something that doesn't? Given the above, the answer is now almost immediate. Again, (1) identically occurs as a constituent in (7), exactly as it does in (6). However, the grammar of (6) and of (7) is again not the same. If the grammar of the right-hand side (RHS) of (7) contained a structurally configured predication of truth, in exactly the way that (1) does when (1) is asserted in isolation, then it would not be puzzling at all that the RHS, if asserted, could be equivalent to the LHS, where a truth predicate is lexically present. The question therefore is: Is the RHS indeed identical to (1), in a grammatically relevant way? For this to be so, the grammar of (1) as occurring in isolation must be similar to the grammar of (1) as occurring in (7), and different from the grammar of (1) as occurring in (6), where we saw no truth-attribution to the proposition expressed in (1) occurs. But this is of course the case. Whereas the grammar of (1) as occurring in (6) is that of a syntactic argument, the grammar of (1) as occurring in (7), is not. (7), unlike (6), is a paratactic, not a hypotactic construction. In traditional terminology (see Hooper \&Thompson, 1973; updated in Heycock, 2006): both (1) as occurring in isolation and as occurring in (7) is in a 'root' (or 'unembedded') context.

Here is, then, why speakers of English and many philosophers find (7) compelling: (7) holds in both directions because the structurally configured predication of truth is present on both sides. If it is also the case that the presence of the lexical truth predicate on the LHS doesn't affect the truthattribution concerned, the equivalence follows. But this condition seems to be fulfilled: true doesn't add to the compositional semantics of an utterance, and it therefore won't affect the status of the two structurally encoded truth-attributions (we return in section 7 to the deeper reason of why the lexical truth predicate should lack such substantive semantic content). ${ }^{8}$

Truth as a root phenomenon is similarly illustrated by clausal adjuncts. In Bill said John left, even though John didn't leave, the clause 'even though John didn't' is grammatically an adjunct, not an argument. Its syntactic connectivity with the syntactic object to which it attaches is looser than when it is

\footnotetext{
${ }^{8}$ This is of course not to say that a formal compositional semantics would not assign a semantic value to 'true', or to 'is true' as a constituent and a perfectly acceptable grammatical predicate of a grammatically referential sentential subject. But the content, in a referential sense, of a proposition does not change if the lexical truth predicate is added to it: the truth predicate applied to a proposition returns the same proposition. Moreover, as noted, 'true' appears to be the only predicate of this sort (as opposed to say probable, possible, ...), showing its special status in the design of language.
} 
an argument, ${ }^{9}$ and in this sense it approximates an independent or root clause. The above account thus predicts that it should again be transparent for truth-evaluation, like the clauses coordinated in (7), where a clause is 'transparent' in this (semantic) sense if it is evaluated for truth directly, rather than as part of a higher predicate denoting a mental state. And of course, the adjunct clause above is transparent in this sense: the speaker asserts it as true that John didn't leave. Two assertions are made: that Bill said that John left, and that John didn't leave. Looking at a range of different clausal types argument, root clauses, or adjuncts - thus confirms our conclusion that when, and when not, a truthattribution occurs, is regulated by grammar, not by non-grammatical kinds of entailments (we return to the notion of root context below and in sections 6 and 7). We will study such further patterns of embedding in the next section, reinforcing and refining these conclusions further, starting with a deeper look at copular constructions. Since this, after all, is what standard truth-attributions such as (5) are, it would make sense to unify their analysis with principled accounts of the grammar of copular constructions in general.

\section{Approximating truth attribution via the copula and its kin}

Constructions where truth attribution is approximated via verbs with reduced lexical content such as seem allow us to fine grain the analysis of truth attribution. We start with a discussion of 'raising verbs' as in (8). They are called that because they allow for the 'raising' (i.e., movement) of the subject of the embedded clause into the matrix subject position (provided the embedded clause is non-finite).

(8) a. It seems that John left.

b. John seems [ _ to have left].

(8) arguably has, apart from the reading in (9), another reading, of which (10) is a relatively close paraphrase (see Ruwet, 1991):

(9) It appears/looks like that John left.

(10) It seems true that John left./ That John left seems true.

While (9) expresses the conjecture or impression that John left, inviting a contrast between an appearance and the reality, this proposition is put forward with somewhat more certainty in (10), or

\footnotetext{
${ }^{9}$ E.g., adjuncts are opaque for extraction, whereas extraction is possible out of arguments, and adjuncts are not canonical recipients of structural Case (see e.g. Chomsky, 2004:116-18).
} 
with more 'truth-theoretic force'. ${ }^{10}$ To be sure, the speaker of (8), under this latter reading, does not quite assert that John left - and indeed, the grammar of (8) itself suggests no such thing, since John left, which is contained in it is not a matrix or root clause. But it is also not quite that the speaker asserting (8) under this reading considers the truth value of the proposition that John left open. Rather, the moment that this doubt was to creep back in, the reading would shift to (9) (and seems is likely to be contrastively stressed in this instance). The truth-theoretic force in question is also clearly stronger than in the case of It seems possible/probable/likely that John left, which does not capture the intuitive meaning and force of (8), at all, under any reading. So true is in fact the right notion to use in (10) in order to bring out the force of (8), under the reading in question. The force is of course also stronger than in (6), where, as we noted, essentially no truth-theoretic force is attributed by the speaker to the embedded proposition.

Taking all of these facts together, we can summarize as follows: the embedded clause in (8), while technically in a subordinated position (since John left is here not a matrix clause), is not in a position as opaque as the one where it occurs in (6). This correlates with the fact that it allows for raising of the embedded subject, as in (8)b. At the same time, it is also not as transparent as that of a root clause (as in (1)), precisely because it is not a root clause. In general, the more transparent a position is, the more it can and will express a truth-attribution. (8), under the reading in question, approximates transparency, while still falling short of it.

This assessment teaches two things. First, the truth predication involved in the truth-attribution to the embedded proposition in (8) and brought out in a lexically explicit way in (10), insofar as a truth attribution takes place, is again not lexically overt. Second, in (10), the truth predicate that is lexically expressed is in fact within the scope of another and structurally expressed truth predicate. For this very reason, what is asserted (to be true) in (10) is that it seems that John left, not that John left. Put differently, the structurally encoded predication of truth overrides the effect of the lexical one, and always has maximal scope. Otherwise the truth that John left would be asserted, which it is not. This

\footnotetext{
${ }^{10}$ The former reading is eased with stress on 'appears' and forced if 'only' is added to 'seems'. For an example, suppose e.g. that John is a house guest and we open the door to our apartment. Nobody there. 'He seems to have left'. This would usually be understood in line with the reading (10). But now suppose we also know that John is a fugitive who is desperate to hide and has been caught hiding before. Again, we open the door to the apartment. 'He seems to have left', we say, stressing 'seems'. This is reading (9).
} 
repeats our earlier observation in a different context: a lexical truth predicate need not induce an attribution of truth: it is not sufficient for a truth-attribution to occur, and insofar as a truth-attribution occurs, it is also not necessary.

By considering the raising verb seem (also called the 'quasi-copula', see Moro, 1997), our picture of the grammar of truth attribution thus gets refined. It gets further fine-grained by considering yet another curious construction, to which little attention has been devoted (but see Moro, 1997).

(11) It's that John left.

If we first compare said in (6) with appears in (9), and then appears with seems in (8), and finally seems with the cliticized copula 's in (11), we see the lexical content of the matrix verb fading away with every step, until eventually it is bleached even morpho-phonologically. As the lexical content of the matrix predicate fades away, the truth-theoretic force of the embedded proposition increases. Thus, as we just argued, (8), under the relevant reading, when asserted, involves some truth-theoretic force attributed to the proposition in question, although, under the relevant reading, it also allows for a certain (low) degree of doubt. In (11), curiously, the truth of the proposition that John left is in fact presupposed or taken for granted. ${ }^{11}(11)$ might for example be an answer to the question 'What's the matter?' or 'What is it?', and when answering this question with (11), the answer could be roughly paraphrased with (12):

(12) It's the truth/the fact that John left. ${ }^{12}$

In line with this, (11) does not have an interrogative version, where the truth value would be in question ( What's it?), thus contradicting its being implied. Even (12) has a redundant feel to it and would hardly be uttered in this form, anymore than It's that John left is true would be, which seems anomalous precisely because the truth of that John left is already implied by (11). The point about the example (11)), then, is that unlike in (5), repeated here,

\footnotetext{
${ }^{11}$ Note that it is not the case that presuppositions require the proposition to be in the common ground. They allow for accommodation. In the sentence: I am sorry that I am late. I had to take my daughter to the doctor, the speaker presupposes both that he is indeed late and that he has a daughter, but neither of these facts need not be known by the addressee.

${ }^{12}$ (11) is not fully grammatical for some speakers of English, though it is for most we have consulted (and it improves with 'just' inserted before 'that'). It is also fine in German (Es ist (nur), dass sie geweint hat) or Italian (C'è que Gianni e partito). For some, (12) with 'the truth' is out. This correlates with the fact that the proposition embedded in (11) is factive (presupposed as true and referenced as a fact), rather than asserted as a truth. We expect this, given the general fact that no proposition, as long as it is embedded at all, is asserted as true (assertion being a matrix phenomenon). The closest we get to truth-theoretic force in an embedded context is factivity (referencing a fact taken to exist) or else an approximation of truth ascription given the right structural configuration (see also further below).
} 
(5) It's true that John left,

again no lexical truth predicate is present, yet again truth is attributed to the proposition that John left, in an stronger fashion in fact than in (8). Ipso facto, again, the phenomenon under investigation here is not lexical. The effect must follow from the grammar and is achieved by voiding the matrix verb of lexical content completely and by thereby avoiding the trap of proper syntactic embedding, which would make the clause non-transparent for truth attribution. How exactly this happens, and how truth is implied in (11) (and, in slighter weaker form, in (8)), will be described in the next section.

\section{Fine-graining the grammar of truth}

The initial analysis above suggests that the difference in the degree of opacity of the embedded clause John left can be traced to purely grammatical facts: namely, the clause occurring embedded in either (8) or (11) is not the syntactically subordinated argument of the matrix verb seems or is, respectively, in the way that it is the syntactic argument of says in (6). Instead, seems in (8) and is in (11) as argued below take a SC as their complements, of which John left is the subject. Whether or not truth is asserted to hold of a given proposition thus depends on such things as whether a clause occurs as a root clause (and hence in a 'transparent' position in regards to truth evaluation) or in an embedded position, and on what kind of embedded position it is (e.g., whether parataxis, hypotaxis, adjunction, a SC, or raising are involved). Since differences in the type of embedding are clearly syntactic in nature, it follows that the attribution of truth is syntactically conditioned. Let us now consider, against this background, the syntax of two constructions that are the most classical ones discussed in the philosophical literature:

(13) That John left is true.

(14) It is true that John left

This literature has touched upon their grammar as well, and we will review some of the earlier analyses first, before starting from scratch, with a new analysis, which aligns their analysis with that of copular clauses in general.

Mulligan (2010) asks which of (13) and (14) is 'more basic', and which one is 'derived'. Fine (1982:44) in turn posits a grammatical 'transformation' that is meant to get us from the latter to the former, where the that-clause is said to be a 'singular term'. Yet these claims are problematic. Generative linguistic theory has crucially never assumed that sentences are transformed into one another. Not sentences but underlying representations of (single) sentences are transformationally related to their 
surface forms. Since (13) and (14) are different sentences, there is no empirical sense in which either is more 'basic' than the other: both are derived from a more abstract underlying representation. Fine's notion of a singular term creates its own problems, from a linguistic point of view. ${ }^{13}$ To start with, it is not a grammatical one, and it is misleading if semantically defined as 'denoting an object' or as a 'referential expression': that John left is not a nominal expression but a clause, ${ }^{14}$ and there is no valid inference, from the analysis that the that-clause in (13) is a grammatical subject, to its being 'object referential', and from there to its being 'nominal'. Such ideas have supported semantic analyses of the above constructions involving various ontological commitments to such 'objects' as propositions or facts. But as noted earlier, 'subject', like 'predicate', is a term indicating how a word or phrase grammatically functions. Since something is a subject only in relation to something else that is predicated of it, there is a sense in which a subject is the referential part of a predication, of which the predicate is the predicative part. For example in (15), the mayor, a nominal, is the subject and used to refer to a particular individual:

(15) The mayor arrived.

However, this nominal need not be so used. Consider (16)a, which we assume, with Moro (1997), is derived from (16)b by moving the subject of the SC, which is the syntactic complement of the copula is, to the matrix subject position, as in (16)c. In this context, then, be behaves like a raising verb. Here the definite nominal the mayor is the predicate (denoting the property of being the mayor), and it is as such not referential, despite its lexical category, which is nominal. ${ }^{15}$ But in (17)a, which we assume is again derived as in (17)b,c, this (non-referential) predicate becomes the (derived) grammatical subject.

(16) a. John is the mayor.

b. is [sc John [the mayor]]

c. John is [sc _ [the mayor]

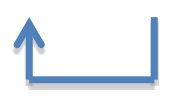

${ }^{13}$ See Betti (2011) for an excellent exposition of other problems with Fine's claim.

${ }^{14}$ The view that it is 'covertly' a noun phrase is critically discussed and rejected in Co-Author and Author (2011).

${ }^{15}$ That the mayor is the predicate of the SC and as such non-referential is confirmed by the answer to the question: 'Who's the mayor?' The natural answer is: 'it's John', not 'he's John' (Mikkelsen, 2005). Similarly, when trying to determine everyone's role in the city, one can ask: 'What is John?' to receive the answer 'John is the mayor.' In this case, what serves as the question word for a predicate. Relatedly, in languages like Catalan, the mayor would be cliticized by the neuter clitic ho, which does not pick out referential expressions. 
(17) a. The mayor is John.

b. is [sc John [the mayor]]

c. [the mayor] is [sc John

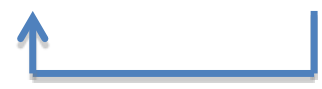

Therefore, 'nominal' does not entail either 'referential' or 'subject', and 'subject' does not entail '(object-) referential'. 'Referentiality', rather, is a grammatical notion, too, and can only be determined in a sentence context: we cannot, as (16a) demonstrates, inspect the words the mayor, and answer the question of whether this phrase is 'referential or not'. ${ }^{16}$ The answer will depend on where in the sentence this phrase occurs and how the sentence is derived. 'Subject' in turn does not entail 'nominal' as noted, even where subjects are grammatically referential and have a presupposition of factivity. ${ }^{17}$ Note in particular that the distribution of CPs (clauses) and DPs (nominals) is different: for example, all that-clauses in English have finite Tenses, whereas no nominals have finite Tenses; and the word that is of category $\mathrm{C}$ that selects a Tense phrase (TP) as its complement - but no such thing happens in nominals. The argument that, because CPs can occur in subject/topic position, they must be nominals, and are (object-) referential, confuses three notions that are empirically distinct: categorial identity (C vs. $\mathrm{N})$, grammatical relations (subject/object), and grammatical functions (referential/predicative).

Let us, then, carefully distinguish these three notions, and return to (13)-(14), taking their grammar more seriously before interpreting it ontologically or semantically, and analysing it in line with copular constructions in general, such as (16)-(17), as seems to be the most natural way to proceed. We will then see that this analysis motivates their semantics as well. Proceeding in this fashion, (13)-(14) are equally derived from an underlying SC that forms the syntactic complement of the copula; 'true' is the predicate of this SC in both cases. However, the SCs in question are different in the two cases. In (13), That John left is the subject of the predicate 'true':

(18) is [sc [cP that John left] true]

This whole subject moves to the specifier of T(ense), yielding (19):

16 That, of course, is equally true for proper names, all of which can (but need not) function as predicates: e.g., 'The track needs more Usain Bolts' (International Herald Tribune). See further Author (2016).

${ }_{17}$ See Haegeman \& Ürögdi (2010), Co-Author \& Author, 2011. None of that prevents either CPs or DPs from functioning referentially, in some syntactic contexts, as the same authors also document, unless referentiality, a grammatical concept, is confused with nominality (which does not entail referentiality as just noted). 
(19) $[[\mathrm{cP}$ that [TP John left $]] \mathrm{T}$ is $[\mathrm{sC}$ true]]

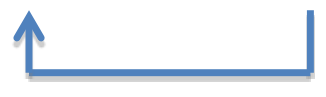

Also (14) is derived from a SC, but this time the subject is the expletive 'it':

(20) is [sc it true]

Again the subject 'it' moves to the sentential subject position:

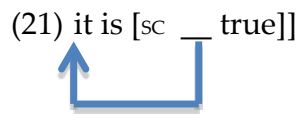

The that-clause, in turn, which functions as the 'associate' of the expletive, forms an adjunct that is extraposed, as the fact suggests that it can be omitted (i.e., It is true is fully grammatical):

(22) [[it is [sc _ true]] [sc that [John left]]]]

This yields an explicit and unified account of the syntax of (13) and (14). How then do we account for their semantics? The most central and obvious aspect of their semantics is that, in both cases, truth is attributed by the speaker to the embedded proposition that John left. This is unlike the case of 'seems' in (8), where we saw that the clause in question arguably has - in some sense and under one reading truth predicated of it, but falls short of full assertoric force. It is also of course entirely different from the case where the same clause occurs in the fully intensional context, as in (6). As a matter of fact, the embedded clause in (13-14) can have no greater assertoric force than when occurring in these very constructions, short of occurring as a root clause itself. Given the earlier correlation between opacity and hypotaxis/subordination, on the one hand, and transparency and parataxis/coordination, on the other hand, analysing the occurrence of this embedded clause as an argument position is therefore out of the question. The above analysis reveals why this is so: in (14), the clause is an extraposed adjunct, with an 'associate' which is the subject of a SC, but equally not an argument of the verb (i.e., the copula), whose complement is the SC as a whole, not the SC's subject; in (13), the clause is not an argument of the verb either. The lack of opacity in (13-14) is therefore, on purely grammatical grounds, exactly what we expect, which in turn supports the analysis above itself.

Having gone over the most classical configurations involved in the attribution of truth, let us now expand the analysis to the quasi-copula seem and ask why, in terms of the opacity of the embedded clause, it forms, as described, a somewhat intermediate case. The intuition we will pursue is that given how semantically weak the copula and the quasi-copula are in terms of their substantive lexical content, 
neither of them can refer to an event that is properly independent of the one referred to by the embedded verb left. In other words, neither the copula nor the quasi-copula have an event position of their own, which would take another event or proposition as argument. In this respect, both (8) and (11) are more like 'mono-eventive' structures, predicting the empirical facts observed, that their embedded clauses will be less opaque than in a clearly 'bi-eventive' structure such as (6) (where there are two events, one of saying and one of leaving). As a result, the embedded clauses in (8) and (11) can carry some truththeoretic force, as indeed they do. Truth predication is paradigmatically a matrix (root, or wholesentence) phenomenon, but raising and copular constructions approximate this phenomenon to some (though crucially not a full) extent. Crucially, the explanation of when and why John left, even if embedded, can have truth-theoretic force in certain instances, is not lexical in any of the cases above, and it does not relate to the fact that the lexical truth predicate 'true' attaches to this proposition in any of these cases. This moreover would not explain the facts in question, any more than it does in Bill considers it true that John left, as we have seen.

We are now ready to present a joint formal analysis of the whole paradigm of truth ascription we have identified thus far, with the relevant data repeated in (23) for convenience.

$\begin{array}{cll}\text { (23) a. } & \text { John left } & (=(1)) . \\ \text { b. } & \text { It seems that John left. } & (=(8)) \\ \text { c. } & \text { It's that John left. } & (=(11)) \\ \text { d. } & \text { That John left is true. } & (=(13)) \\ \text { e. } & \text { It is true that John left } & (=(14))\end{array}$

(23)c is grammatically exactly like (23)e, except that there is no lexical truth predicate in it at all, despite the fact that a presupposition of truth is clearly present, as noted. While ungrammatical when used out of context, (23)c can be a felicitous answer, but it is not the same assertion as (23)a. Rather, the truth that is normally stated in (11), is, as Moro (1997:196) puts it, is somehow 'reinforced', and it is being referred to, as in It's the fact/truth that John left. If we want to have this structure as patterning with the it is true construction and the it seems construction, and with copular constructions in general, we have essentially only two options: we will begin with a SC forming the complement of the copula BE, and that can logically either be the one in (24) or the one in (25), in which the roles of subject and predicate have simply reversed: 
(24) 's [sc it [cP that John left]]

(25) 's [sc [cP that John left] it]

In short, it is either the subject of the SC, as in (24), or its predicate (25). There do not seem to be other options. As Moro (1997) argues at length, several empirical facts suggest it functions as a predicate as in (25), and we will adopt this analysis here.

One might object that it as a pronoun may not plausibly be a predicate. But there is no particular $a$ priori reason why an NP such as it should not to play the role of (or to stand in for) a predicate, since as we already saw, definite nominals can be predicates (16). We also saw that nominal predicates in such constructions can become subjects (the 'inverted' case) (17). In line with this, the analysis of it as a predicate (i.e., (25)) will allow us to analyse (11) as an instance of the 'inverse' option available in copular sentences of this type: the SC-predicate (it) moving over the SC-subject (that John left) into subject position. Evidence for this analysis comes from sentences that clearly involve a SC such as (26), where consider takes a SC complement. Crucially, in this case predicate 'inversion' over the SC-subject requires a copula as the contrast between (27) and (28) shows.

(26) I consider [sc John [NP the problem]]

(27) *I consider [sc the problem [NP John]]

(28) I consider [sc the problem to be [NP John]]

Therefore, if (25) rather than (24) was the right structure, hence it was the SC-predicate and it inverts over the subject. This structure should be ungrammatical when to be is omitted, just as (27) is. And indeed, it is ungrammatical, as the contrast between (29) and (30) shows. (Note that (30) requires some context to be well-formed. For example, it can be used to answer the question What do you consider the problem?):

(29) *I consider it that John left.

(30) I consider it to be that John left.

Similarly, if we replace it with a full DP, we observe the same pattern: the copular to be has to be spelled out. This suggests again that the CP functions as the subject and the DP as the predicate.

(31) *I consider the $\{$ fact/truth/claim/assumption $\}$ that John left.

(32) I consider the $\{$ fact/truth/claim/assumption $\}$ to be that John left. 
Finally, if indeed it played the role of the predicate in (11), we would expect that, along with the option where the predicate vacates the SC and inverts over the SC-subject, there should be another case where the SC-subject vacates the SC and leaves the predicate it in its base position. In principle, this option should yield a well-formed construction, namely (33), which is however ungrammatical seemingly contradicting the above analysis.

(33) *That John left is it.

There is in fact a compelling independent reason for why (33) should be ungrammatical, however: it, is a dummy predicate, a 'pro-form' without lexical content. Being a nominal, even if it functions as a dummy predicate, it requires case and needs to move to subject position for this reason. Inversion of the predicate over the subject is therefore plausibly obligatory, and (33) is predicted to be out on independent grounds (Moro 1997: 177). We therefore suggest that the structure of (11) is (34).

(34) it is [sc [that [John left] _ _]

But the analysis arrived at in (34) still throws up the question of why the grammar would make available a dummy pro-predicate $i t$. Given the semantics of the construction, the answer is now clear: in the absence of a lexical predicate in the SC, and given that the matrix copula lacks an event-position, the grammar can realize the structure required for the attribution of truth only by resorting to a dummy predicate within the SC. Thus, it is inserted to assemble the configuration required for truth attribution. And this is its only function. ${ }^{18}$

If this explanation holds water for the copula, it should also apply to the 'quasi-copula' seems, and explain its intermediate status between full lexical verbs and the copula. Hence we propose that the structure for (8) should be (35), just as (34) is the structure for (11), where it in (35) has moved from the predicate position in the SC to matrix subject position.

(8) It seems that John left.

(35) it seems [sc [that John left] _ $]$

\footnotetext{
${ }^{18}$ The question still remains why the grammar would choose the pronominal element it as the predicate, rather than, say, the dummy verb do which may be used as a dummy auxiliary (John left and Mary did too). It could be that the reason is that as a verb, do is intrinsically associated with an event argument, and hence cannot remain dummy when inserted in a lexical predicate position. No such event argument is associated with the pronominal it.
} 
By contrast, when the lexical truth predicate is present in the it seems construction, the structure is (36), with that John left an 'extraposed' adjunct that is the 'associate' of the expletive subject, as was the case in (22):

(36) [it seems [sc _ true]] [that John left]

In further support of the presence of a dummy predicate in (35), consider that (37), where John is raised from the position of the subject of the embedded clause to the subject positon of the matrix clause, is fully grammatical, while (38), from Moro (1997:195), is out:

(37) John seems [__ to be sad] 'John seems to be sad.'

(38) *it seems [for John to be sad]

This data would follow if (35) is correct. For if the SC in (35) assembles the structure for a truthattribution, the predicate necessarily requires a truth-evaluable constituent to apply to. But the nonfinite clause in (38) doesn't qualify as such, as we independently know: no truth can be grammatically predicated of it, as evidenced by the ungrammaticality of the sentences in (39).

(39) a. * $\quad$ [for John to be sad] is true

b. $\quad *$ It's true to be sad.

By contrast, John left in (8) is not only truth-evaluable, but indeed truth-evaluated (to a degree). Also predicted is that (40)a is ungrammatical whereas(41)a is fully grammatical. The explanation transpires when we accord the structural analyses in $(40) \mathrm{b}$ and $(41) \mathrm{b}$, respectively.

(40) a. $\quad$ *It's that John left obvious

b. $\quad$ *it is [[that John left] obvious]

(41) a. That John left is obvious.

b. [[that John left] is [__ obvious]]

In (40), it, which as just argued must move, cannot be moved from the predicative base position, where there is a predicate already (Moro, 1997:183). (42), by contrast, should be possible, since it plays the role of subject in it, while obvious is the predicate (with the finite clause again an extraposed adjunct, as suggested by the fact that it can be grammatically omitted as indicated by the brackets):

(42) It is obvious (that John left).

That this is indeed a different type of construction can be gleaned from the fact that subject raising is no longer an option, as the ungrammaticality of (43) indicates. 
(43) *John seems obvious [__ to have left]

Note further that, unlike it, obvious cannot move to matrix subject position, as shown in (44).

(44) a. $\quad$ *Obvious is that John left.

b. [obvious is [that John left]

This follows from our analysis because it is nominal and hence moves to matrix subject position to receive case. As an adjective, obvious does not require case and hence cannot move. Why, finally, can we say It seems that John left, but not *That John left seems? The latter is excluded because the SC of which the that clause is the subject would remain without a predicate as in (45); and where this predicate is spelled out as the dummy predicate it, it must move:

(45) *[That John left] seems [sc PRED]

By contrast, we expect That John left seems true to be fine, as it is.

This proposal analyses (8) and (11) as being identical in terms of the SC structure involved, in line with an essential interpretive similarity between them: they both cannot be felicitously uttered if it's presupposed that John didn't leave. ${ }^{19}$ On the other hand, their interpretive differences follow from the different character of their matrix verbs, seems vs. 's: lexical content is even more bleached in the latter than in the former, which means that the latter approximates even more closely a mono-eventive structure. In line with this difference, seem can assign a thematic role (experiencer) (47), while 's cannot (46):

(46) *It's to Peter that John left

(47) It seems to Peter that John left

And 's allows nominal complements (48), but seems does not (49):

(48) It's the birthday party.

(49) *It seems the birthday party.

This follows again if seem, though still not fully lexical, does have some thematic structure and projects a clause of its own, approximating a bi-eventive structure. In this case the complement it selects needs to be clausal as well, corresponding to a proper truth predication, which the birthday party is not. By contrast, in (48) there is no requirement of a second event-argument and we get away with a nominal

\footnotetext{
${ }^{19}$ In the case of (8), this circumstance would only be consistent with a focal stress on seems (It (only) seems that John left), which immediately shifts the reading to the other one distinguished above (seems as appears/looks like).
} 
SC subject, which in this case is interpreted factively as picking out a birthday party that is contextually given.

This completes our unified analysis of the whole paradigm of truth attributions listed in (23), repeated here as (50):

(50) a. John left.

b. That John left is true.

c. It is true that John left.

d. It seems that John left.

e. It's that John left.

All of these, we observed, are similar in that: (i) there is no proper subordination of the clause John left as a syntactic argument; (ii) the speaker maintains the truth of this clause, either by asserting it (a), reasserting it $(b, c)$; essentially assuming it (d), or presupposing it (e). Under our analysis, the lack of subordination under a matrix verb with full lexical content, together with the presence of a dummy propredicate in (50)(d) and (e), provides the configuration for truth-attribution. This reinforces our earlier conclusion that whether or not truth is asserted to hold of a given proposition intrinsically depends on intricate details of the grammar of the expression. It is not a lexical phenomenon, for it depends on such things as whether a clause occurs as a root clause (and hence in a transparent position in regards to truth evaluation) or in an embedded position, and on what embedded position it is (e.g., whether parataxis, hypotaxis, adjunction, or raising are involved). In general, opacity is maximal (and transparency minimal) when the clause occurs as a properly hypotactically embedded syntactic argument, as in (6). As we move to more mono-eventive structures, where the embedded clause is not a syntactic argument of the matrix verb, opacity is slightly lifted, and the right configuration for truth attribution may ensue, as we have just seen. As we move to matrix clauses, finally, or to coordinative or paratactic constructions, it is lifted completely.

\section{Truth and the limits of grammar}

Truth attribution, we have said, is a paradigmatic root phenomenon, linked to utterances as wholes. It is here where clauses are put forward as true in relation to the world, rather than as something that is true relative to the mental representations of others, what seems to them to be true, or is presupposed by them to be the case. It is where language connects to reality, not to appearance or thought. What lends 
confidence to this special role of the root is that the same direct connection to the world is also seen in other root phenomena, including vocatives, certain interjections, and imperatives: although truth is not an option in any of these, the same direct world connection is seen. To begin with vocatives, if I shout (51), I directly refer to John, who must be a part of the speech context (or must be taken to be):

(51) John!

Reference is no more open or undecided here than we have argued truth is in an utterance of (1). Both are root phenomena, illustrating, now in the nominal case and for the notion of reference, the correlation we have argued for. In line with this analogy, when proper names occur in embedded positions, we see that their referential properties can change, and reference becomes less direct. Thus, in (52), where John occurs as an embedded, subordinated argument, the speaker clearly doesn't ipso facto refer to John, in the sense that there is some direct or causal connection to him within the speech context (whether or not we think of proper names as 'rigid designators', see Author, 2016). ${ }^{20}$

(52) I called John yesterday.

This is even more obvious in (53) and (54):

(53) I have no idea who John is.

(54) Are you John?

Root uses of proper names (such as vocatives) thus connect with the external world in ways that embedded uses of them do not, paralleling what we observed for clauses. Only the former uses can properly be described as 'indexical'. Similar observations apply to interjections, as in (55):

(55) Sh...!

Whoever says (55) doesn't leave reference open: it will be immediate from the circumstance of use what Sh... refers to. The same is true of the actions that imperatives such as Come! refer to: nothing here can drive a wedge between the utterance and the action it refers to. In line with this, imperatives cannot be

\footnotetext{
${ }^{20}$ To avoid major misunderstandings, note that we are crucially not saying that lexical proper names necessarily refer directly to an individual in the speech context. Of course, they don't, in general, but they do so in a certain grammatical configuration, namely one that supports a vocative interpretation, which is the case in (51) but not in (52). Specifically, in (52) John functions as an argument, and argumenthood is in complementary distribution with a vocative interpretation. This supports the view that reference, is grammatically configured, and hence is compatible with the claim that truth, a special kind of reference, is grammatically configured. (51) is only felicitous when John is present in the speech context and called upon. (52) is only felicitous when he is not.
} 
embedded..$^{21}$ The same applies to the intended subject of the action, which is often silent referring to the addressee of the imperative. However, it may also be overtly realized (You come here now!) and although it is not always you (Everyone come here now!), it always refers to the addressee(s) which are part of the speech act.

Between utterances that are single words, interjections, or verbs, and utterances that can assert truth, there is grammar: starting from a lexicon, grammar builds phrases, and then hierarchical relations between them. A first class of these are 'thematic' relations, none of which are lexical. Thus, (57) expresses what (56) does:

(56) John insulted Fred.

(57) The Agent of the insult (which took place prior to now) is John, the Patient is Fred But (56) does not overtly express the thematic concepts of Agency and Patiency, though it clearly contains them, configurationally, in just the way we have argued that truth is a configurational notion. Yet there is a crucial difference between these two cases: thematic relations are not root phenomena and they do not interface with the context. Thematic structure is projected based on lexical knowledge of verbs. It is not merely that thematic relations are early in the structure-building process and truth is late, however, but that when truth is configured, an important boundary in grammar is reached: at this point, grammatical structure building with an associated compositional semantics based on lexical content words stops, as does recursion. To explain this, consider that at this point, no question can be derived, since if it was, the truth value would be erased.22 Or consider that, having assembled (1), we would add a new clause I said that, to derive (58).

(58) I said that John left.

Again, in this case, the truth value associated to John left when asserted in isolation would be lost. Moreover, (58) only re-assembles the basic Aristotelian template that a statement of truth exploits, with $I$ as the subject, say that John left as the complex predicate, and Tense marked as an inflection on the

\footnotetext{
${ }^{21}$ For some necessary qualifications, see Schwager, 2006, who shows that in some contexts embedded imperatives are possible. However, they are usually more constrained than embedded interrogatives or declaratives, which are already constrained. According to Kaufmann (2014), they appear in reported speech contexts and come with syntactic and semantic restrictions. Thus, imperatives can only embed when particular conditions are met. What derives these conditions, and how they relate to the present proposal is beyond the scope of this paper.

${ }^{22}$ Assuming that interrogatives are derived by transforming (i.e., un-doing) the very configuration in question: John is here $\rightarrow$ Is [John _ here].
} 
matrix verb (leading to the spell-out of say as said). The newly arising complex (or recursive) sentence thus does not have any different structure from that of a single sentence: it still only has a single subject, a single (complex) predicate, a single Tense determining the reference time relative to the speech time (past), ${ }^{23}$ and (most crucially) a single truth value: What is assigned a truth value here is the fact that I said that John left, not that John left, as we have seen. In summary, not being asserted for truth is the price paid for being embedded, and if embedding happens, this neither changes the basic configuration in which truth is asserted, nor that it is a single truth value that is assigned: no utterance, no matter how complex, ever distributes asserted truth over both matrix and embedded clauses. Truth, attribution, in this sense, is a 'maximal' phenomenon in the architecture of human grammar.

This assessment extends to modal modifiers, as in (59):

(59) Possibly, John left.

What is asserted here is again not that John left, but that he possibly did. Truth is involved, since it is the truth - not the probability, credibility, or desirability, say - of John's having left, which is said to be possible. Nonetheless, exactly as before, we see that the occurrence of this predication of truth in the scope of the modal possibly, wipes out its truth-theoretic force: no truth to the effect that John left is being asserted. The situation changes in this regard with clausal adjuncts, which in principle can be added in arbitrary numbers to every fully configured assertion (John left, without any doubt, before noon, because he was late..., all of which entail John left). Every adjunct functions as a (grammatically optional) further specification of the truth claimed - none of which changes this truth as such, or the fact that it is attributed. Adjunct clauses differ from modal modifiers, in short, in that the latter wipe out truth attributions in clauses in their scope, while adjunct clauses leave them unaffected. That is in line with what adjuncts are: they do not change fundamental grammatical configurations. The case where truth attribution is preserved, in short, is also the case where grammatical relations are maintained.

Beyond adjuncts, we can also add tags, evidentials, and discourse markers to an utterance in which truth is predicated, and like adjuncts, none of these will change the fact that truth is predicated: truthconditional semantics is preserved, while what changes is how truths put forward are embedded in

\footnotetext{
${ }^{23}$ Of course, there is an embedded Tense (specified on left). However, at the matrix level, Tense is evaluated as indexical in relation to the point of speech (the Now of the speaker), and embedded Tenses are evaluated differently, namely at least partially in relation to the temporal reference point established by the matrix Tense. In particular, (6) has a reading where what Bill said is John left, hence where the leaving took place prior to the saying (Giorgi, 2010).
} 
discourse and social interaction. In the case of inflectional morphemes expressing evidentiality, say, the assertion stands, but what is added is an indication of its epistemic source. This difference to the case of modals interestingly correlates with a difference in the grammar of evidentiality markers as compared with that of modals (or adjuncts): while modals are recursive to some extent (e.g., Evidently, John possibly left), evidentials lack this property almost completely, in a similar way as English tag-questions do (cf. John left, didn't he?, but not *John left, didn't he, did he?). At the point in a syntactic derivation where the truth value has been assigned, in short, the process of adding structure is not recursive and it also won't change the truth-conditional compositional semantic content of the assertion made. Truth value assignment in this way points to a fundamental limit imposed on recursion in grammar, beyond which grammar regulates very different aspects of meaning, to do with the sources of evidence, speakers' attitudes, speakers' assessments of the addressee's attitudes, turn-taking management, etc.

Of course, when (1) is uttered, another person may hear this utterance and also hear it doubted. Thus, she may want to re-confirm it. This moment, where the epistemic subject changes, is the moment where the lexical truth predicate acquires its crucial function. For this person may now utter (60).

(60) It's true that John left.

Although this adds nothing to the compositional semantic content of (1), it does involve a change in indexicality, in the sense that the predication of truth in (60) will often be indexed to a different speaker (or epistemic subject) than the assertion of (1) to which (60) reacts. If so, however, there is then still a single structural predication of truth, necessarily indexed to the speaker in the actual act of utterance. Where more lexical truth predicates are recursively added, and the epistemic self remains the same, a reading is derived in which, with every new round of iteration, the message gets ever more intense (until one feels this must be the speech of a maniac):

(61) It's true that it's true that it's true that John left.

One could attach it is false to an assertion of it is true that John left, and thus change the semantic predicate. This does yield a compositional semantic effect - which is exactly what we predict from the fact that negation unlike truth is always lexically overt and a paradigmatic example of an element that yields a compositional semantic effect. But any such negative element will necessarily be in the scope of sentential truth predicate (we can assert a falsehood, but we can only do so by asserting (as true) that something is false - it is not the case that $P$ ). 
This account derives a prediction for those constructions in which there is some assumption or presupposition of truth in place, although there is no lexical truth predicate: namely (apart from of course (1)) the raising construction with seems in (8) and the copular construction in $(11 /(23) \mathrm{c})$ : If, in these constructions, with the help of the pro-predicates that we argued they contain, the basic skeleton of a truth-attribution is assembled, an iteration of these constructions should be difficult or out. Consider, then, to test this prediction, attempts to perform such iterations in (62) and (63).

(62) *?it's that it's that John left

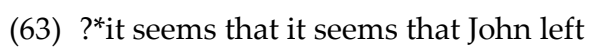

Judgements on these constructions differ. For the present authors, the second at best only has the reading where the first seems has the reading of appears distinguished earlier; and (62) is essentially uninterpretable. As we noted, the meaning of (23)c (It's that John left) is similar to It's the fact that John left. And the above predicts why we cannot go further than that: having made reference to a fact in this construction, we can't make reference to this reference, as it were. We have reached the limits of truththeoretic grammar. And hence, on the above hypothesis, we should not be able to iterate: recursion is halted. Where the lexical truth predicate occurs, idle or even non-idle (as in the case of an indexical shift) iterations are possible; yet, as we have also argued, truth as structurally expressed is the more fundamental phenomenon, and that phenomenon does not iterate.

So root phenomena take us to the outer limits of grammar, and we are now ready to connect these purely grammatical considerations to a curious and seemingly non-grammatical fact about an apparent limit imposed on what we may call the 'semantic ontology of natural language' (Moltmann, 2013). In this ontology, metaphysicians have commonly distinguished between 'propositions' and 'facts' as possible referents for natural language expressions. For example, we might wonder whether John left; and once we have established that, we might utter (64).

(64) It's a fact that John left.

For at least intuitively, a fact is semantically similar to a proposition that is (or has been) evaluated as true. If we say (64), however, we usually consider the matter settled. In no human language there seems to exist a third ontological category - call this fictional category 'pact' - such that, once it was challenged that (1) is indeed a fact, as claimed in (64), and we concluded that (64) was indeed correct, we could 
comment as in (65), with the semantics that the fact has now been converted into a pact, just as we previously converted a proposition into a fact:

(65) It's a pact that John left.

More fundamental than facts, in other words, things don't seem to get; truths can, at best, be facts, and this is it. ${ }^{24}$ Truth itself, in that specific sense, is not recursive either, and doesn't iterate - even the fact that something is a fact, is still not ever anything other than a fact. This, moreover, is not simply a metaphysician's theoretical decision or choice: rather, we find ourselves confronted, in thought, with a limit on the formal ontological complexity of meaning. Why should there be this curious restriction on the ontological categories involved in the semantics of natural languages? If we can move from propositions to facts (with the latter category being ipso facto truth-involving in a way that propositions are not), why can't we move further?

One answer is now natural: this restriction reflects an analytic truth of grammar. Anything more complex than truths, the grammar cannot compute. Truths about truths are just truths again, and nothing more, or deeper. The configuration of truth brings the process of generating the complexities of compositional semantics to a close. In terms of categorial complexity, nothing happens after that. ${ }^{25}$ There is thus a hierarchy of semantic evaluations: we can evaluate an object for its colour or beauty, an act for its morality, or a proposition for its possibility or desirability. But evaluations like the former two will happen inside of clauses, and evaluations like the latter will be in the scope of evaluations for truth.

\footnotetext{
${ }^{24}$ Even if this was true of natural language and ordinary talk, one referee points out that there is a flurry of recent work in metaphysics devoted to 'grounding' facts (Fine, 2012; Rosen, 2010; Schaffer, 2009; Sider, 2018). While this point deserves a wider discussion than is possible in the confines of this paper, the metaphysical issue arises from the desire to 'ground' some (not so fundamental) facts in other (more fundamental) ones. This issue of connecting 'levels' does not entail the existence of a more fundamental formal-ontological category like the putative 'pact'. At whatever level of facts reality's rock-bottom is reached, we cannot dig deeper.

${ }^{25}$ This also explains why it is much more felicitous to answer (i) with (ii), than to answer (iii) with (iv):

(i) You studied in Leeds.

(ii) True.

(iii) It is true that you studied in Leeds.

(iv) *True.
}

Evaluation for truth marks a crucial boundary in the growth of structures in human grammar: when that boundary is reached and the truth predicate is applied, structure-building and semantic composition stop. 
A more basic or fundamental level of semantic assessment - more abstract even than truth - does not seem to exist. ${ }^{26}$

In summary, we have now considered embedding clauses, modals, adjuncts, evidentials, tags, and lexical truth predicates: once a configuration is assembled that can effect a truth-attribution, any of these can be added. Sometimes, this is possible in an unbounded recursive fashion; sometimes not. Where not, this illustrates that the grammatical process has come to an end with the configurations obtained; where it is possible, the recursion re-assembles the same template in the next step, but the template never changes and the structural truth predicate will never iterate or become recursive: a critical boundary in the build-up of structural complexity in grammar is reached. This is why, when the lexical truth predicate is now added, nothing in the compositional semantic content changes, and it can also be dropped again, as Tarskian equivalences suggest. With this we are ready to draw a final, philosophical conclusion.

\section{Conclusion: Grammar, deflationism, and truth}

A central 'deflationist' contention is that the truth predicate has no substantive empirical content, in the way that blue does, or water (its significance, if any, is functional or quantificational). Yet we may want to know why this is so - rather than treating this lack of substantive content simply as a brute metaphysical fact of truth. We can now envisage an informative and empirical answer to this question: because truth is a grammatical concept. Being structural in nature, as argued in this paper, we do not expect it to have a substantive lexical content of this sort, and we have a positive reason to conclude that the search for an external metaphysical relation of truth - in the way that we may want to assume a relation between water and the substance $\mathrm{H} 2 \mathrm{O}$ that it denotes - is misguided, exactly as the deflationist contends. The function of truth in grammar is to bound, rather than extend, the compositional process applying to lexical meanings and leading to the configuration of a proposition. When this boundary is reached, semantic valuation for truth takes place and no compositional and truth-conditionally relevant content can be added. Using grammar to compose words converges towards this boundary, and it never could do anything else: grammar could not be used to only derive interrogatives, vocatives, or imperatives. It cannot be used other than to state truths.

\footnotetext{
${ }^{26}$ Again this appears to be orthogonal to the metaphysician's desire to ground (some) facts in others. See footnote 24 .
} 
We have also made intelligible why the Tarskian Equivalence scheme, the centrepiece of the deflationist edifice, should intuitively hold (at least for sentences not themselves containing the truth predicate). The explanation is: there are two forms predicating truth, one lexical and one structurally expressed, and the second is present even where the first is not, in a root context. Taking these two points together, our account vindicates and derives the deflationist intuition that the truth predicate has no real-world, empirical, or substantive content, and that therefore no naturalistic or reductive analysis is appropriate for it (Horwich, 2010). Its content is purely grammatical, and our understanding of the notion of truth reduces to our competence in handling a specific grammatical configuration. In some ways, truth is like gender: metaphysical conclusions should not be drawn from truth as configured in grammar, anymore than conclusions about the nature of an object should be drawn from the way that a noun denoting it is subcategorized for gender. As long as we adopt a naturalistic stance towards grammar, our findings thus also have the benefit that they pave the way for a naturalization of truth on grammatical grounds.

\section{References}

Aikhenvald, A. 2004. Evidentials. Oxford University Press.

Author; 2003; 2012; 2015; 2016; Co-author and Author. 2011; Author and co-author, 2015.

Betti, A. 2015. Against facts. Cambridge, MA: MIT Press.

Chomsky, N. 2004. Beyond Explanatory Adequacy. In Structures and Beyond, ed. A. Belletti: 104-31. Oxford: Oxford University Press.

Davidson, D. 2005. Predication and truth. Oxford University Press.

Davies, W. D. \& S. Dubinsky 2009. On the Existence (and Distribution) of Sentential Subjects. Gerdts, D. B., J. C. Moore \& M. Polinsky (eds.), Hypothesis A/Hypothesis B. Linguistic Explorations in Honor of David M. Perlmutter, Cambridge, MA: MIT Press, 111-128.

Delahunty, G. P. 1983. But Sentential Subjects Do Exist. Linguistic Analysis 12, 379-398

Den Dikken, M. 2006. Relators and Linkers. Cambridge, MA: MIT Press.

Emonds, J. 1972. A reformulation of certain syntactic transformations. Peters, S. (ed.), Goals of Linguistic Theory, Englewood Cliffs, NJ: Prentice-Hall, 21-62.

Fine, K. 1982. First-Order Modal Theories III-Facts. Synthese 53: 43-122. 
Fine, K. 2012. Guide to Ground. In Fabrice Correia and Benjamin Schnieder (eds.), Metaphysical

Grounding: Understanding the Structure of Reality, 37-80. Cambridge: Cambridge University Press.

Giorgi, A. 2010. About the speaker. Towards a syntax of indexicality. Oxford University Press.

Haegeman, L. and B. Ürögdi 2010. Referential CPs and DPs. Theoretical Linguistics 36 -2/3, 111-152.

Heycock, C. 2006. Embedded Root Phenomena. In M. Everaert \& H. van Riemsdijk (eds.), The Blackwell Companion to Syntax, Vol. II, 174-209. Oxford: Basic Blackwell.

Höhle, T. 1992. Über verum-fokus im deutschen. In Jacobs, J. (ed.), Informationsstruktur und Grammatik, 112-141. Westdeutscher Verlag.

Hooper, J. and S. Thompson. 1973. On the applicability of root transformations, Linguistic Inquiry 4, 465497.

Horwich, P. 2010. Truth, meaning, reality. Oxford University Press.

Iatridou, S. 2000. The grammatical ingredients of counterfactuality. Linguistic inquiry, 31(2), 231-270.

Kaufmann, M. 2014. Embedded imperatives across languages: Too rare to expect, too frequent to ban. Handout for presentation at Colloquium Stony Brook, April 4, 2014.

(https://semanticsarchive.net/Archive/GU5OGQ4N/kaufmann_HO2014_embedded_imps.pdf).

Koster, J. 1978. Why subject sentences don't exist. Keyser, S. J. (ed.), Recent transformational studies in European languages, Cambridge, MA: MIT Press, 53-64.

Lackey, J. 2007. Norms of assertion. Nous 41:4, 594-626.

Laka, I. (1994). On the Syntax of Negation. Outstanding Dissertations in Linguistics Series, New YorkLondon: Garland Publishing Co..

Lohndal, T. 2013. Sentential subjects: topics or real subjects. In Santana-LaBarge, R. (ed.) Proceedings of the 31st West Coast Conference on Formal Linguistics (WCCFL 31). Cascadilla, MA: Cascadilla Proceedings Project.

Mikkelsen, L. 2005. Copular Clauses: Specification, predication and equation. John Benjamins.

Moltmann, F. 2012. ‘Truth Predicates' in Natural Language. In D. Achourioti / H. Galinon / J. Martinez / K. Fujimoto (eds.): Unifying the Philosophy of Truth. Dordrecht: Springer, 57-83.

Moltmann, F. 2013. Abstract objects and the semantics of natural language. Oxford: Oxford University Press. Moro, A. 1997. The raising of predicates. Cambridge University Press.

Mulligan, K. 2010. The Truth Predicate vs the Truth Connective. Dialectica 64, 565-584. 
Rosen, Gideon (2010). Metaphysical Dependence: Grounding and Reduction. In Bob Hale and Aviv Hoffmann (eds.), Modality: Metaphysics, Logic, and Epistemology, 109-36. Oxford: Oxford University Press.

Rosenbaum, P. S. 1967. The grammar of English predicate complement constructions. Cambridge, MA: MIT Press.

Ruwet, N. 1991. Syntax and Human Experience, University of Chicago Press.

Safir, K. 1985. Syntactic Chains. Cambridge: Cambridge University Press.

Schaffer, J. 2009. On What Grounds What. In David J. Chalmers, David Manley and Ryan Wasserman (eds.), Metametaphysics, 347-83. Oxford: Oxford University Press.

Schwager, M. 2006. Interpreting Imperatives. PhD thesis. University of Frankfurt.

Sigurdsson, H. A. 2004. The syntax of Person, Tense, and speech features. Italian Journal of Linguistics 16:219-251.

Stowell, T. 1981. Origins of Phrase Structure. Ph.D. thesis, MIT.

Williams, E. 1980. Predication. Linguistic Inquiry, 11(1), 203-238. 